REVISTA DE DERECHO UNED, NÚM. 22, 2018

\title{
LA REPRESENTACIÓN POLÍTICA DE LAS CORTES DE CASTILLA DURANTE LOS AUSTRIAS
}

\section{THE POLITICAL REPRESENTATION OF THE PARLIAMENT OF CASTILE DURING THE AUSTRIA}

\author{
HÉctor ÁlVAREZ García \\ Profesor Ayudante Doctor de Derecho Constitucional. \\ Universidad Pablo de Olavide
}

Resumen: El trabajo tiene por objeto analizar la naturaleza representativa de las Cortes de Castilla durante los siglos XVI y XVII. Sus orígenes se encuentran en los concilios de la monarquía visigoda y en las Cortes de León de 1188, a las que concurrieron por primera vez en la historia política europea representantes del tercer estado. Asimismo, estudiaremos la relación jurídico-política que ligaba a los procuradores de Cortes con sus ciudades (mandato imperativo) y la dialéctica Cortes del Reino versus Cortes de las Ciudades (mandato representativo vs mandato imperativo), que tuvo lugar durante el reinado de la dinastía Habsburgo en España.

Abstract: The work aims to analyze the representative nature of the Parliament of Castile during the sixteenth and seventeenth centuries. Its origins are in the councils of visigothic monarchy and in the Parliament of Leon of 1188, to which representatives of the third state participated for the first time in European political history. Likewise, we will study the juridical-political relationship that linked Parliament's representatives with their cities (imperative mandate) and the dialectic Parliament of Kingdom versus Parliament of Cities (representative mandate $v s$. imperative mandate), which took place during the dinasty Habsburg's reign in Spain. 
Palabras clave: Cortes de Castilla, representación política, mandato imperativo, mandato representativo.

Keywords: Parliament of Castile, political representation, imperative mandate, representative mandate.

Recepción original: 18/09/2017

Aceptación original: 12/12/2017

Sumario. I. El origen del Parlamento. I.A. Los concilios de la monarquía visigoda. I.B. Las Cortes del Reino de León. II. La monarquía dualista estamental. III. La naturaleza representativa de las Cortes de Castilla. IV. Mandato imperativo versus mandato representativo.

\section{EL ORIGEN DEL PARLAMENTO}

\section{I.A. Los concilios de la monarquía visigoda}

La génesis del Parlamento en el Viejo Continente se halla en las Cortes del Reino de León de 1188. No surgieron por ensalmo - como Minerva de la cabeza de Júpiter- sino que fueron el resultado de un lento proceso de evolución institucional, cuyo origen se encuentra en los concilios de la monarquía visigoda.

La abjuración del arrianismo y la solemne profesión de la fe católica hechas por Recaredo y los nobles en el Tercer Concilio de Toledo (589) conectaron la península ibérica con la comunidad hispanorromana. Supuso una inflexión en la organización institucional —naturaleza político-eclesiástica de los concilios-y en las relaciones de poder del Imperio gótico: la ascendencia de la Iglesia en los asuntos gubernativos.

Así, de ser sínodos en los que se debatía sobre materias teológicas, litúrgicas o morales y a los que sólo acudía la alta jerarquía eclesiástica, los concilios se convirtieron en asambleas mixtas, integradas por nobles y prelados, en las que se decidían también cuestiones relativas al gobierno temporal.

«(...) el hecho fue que, apartando los concilios de su primitivo y especial instituto, llevó á ellos los negocios de Estado, y les hizo tomar una parte, no bien definida, no permanente, pero sin duda alguna real y verdadera, en las más arduas atribuciones de la soberanía (...). Los sínodos, asambleas eclesiásticas hasta allí, comenzaron á hacerse políticos, sin cambiar por eso esencialmente en su constitución: el poder 
de los soberanos sufrió por este medio un amenguamiento considerable $(\ldots){ }^{1}$.

En el Reino visigodo de Toledo el monarca convocaba los concilia cuando necesitaba resolver los ardua negotia regni, que exponía en el discurso inaugural que abría las sesiones conciliares. Los concilios estaban formados por los nobles, algunos de los cuales integraban el Aula Regia -órgano político de asesoramiento áulico-, los prelados y el pueblo. Sin embargo, sólo los próceres de la sociedad visigótica tenían voz y voto en la asamblea política.

«Estos congresos eran unas juntas de personas muy señaladas por su virtud, por su prudencia, mérito y talentos y por los grandes conocimientos adquiridos con la práctica de los negocios: personas que en cierta manera representaban el reino porque su reunión se encaminaba a tratar de la común felicidad y a hacer lo que el pueblo haría en semejante coyuntura ${ }^{2}$.

La participación del pueblo era imperfecta: «asistiendo á las deliberaciones como espectador y aclamándolas como quien debía prestarles obediencia; y así la frase omni populo assentiente no significa que fuese necesario para la validez de las normas el concurso de la voluntad popular, sino tan sólo que la adhesión unánime de los circunstantes robustecía lo acordado por los obispos y la nobleza con la promesa de guardarlo en todas sus partes bajo la promesa de un público juramento.

Esta asistencia del pueblo á los concilios se explica por la naturaleza mixta de tales asambleas, pues según la antigua disciplina de tales asambleas, solían congregar los Padres á los fieles y publicar en su presencia los cánones establecidos (...). Junta esta razón canónica á la tradición conservada en el pueblo godo de intervenir en los graves negocios del reino, como en la elección de Wamba se manifiesta ${ }^{3}$, resulta un doble motivo de asistir a los concilios de Toledo para aclamar y recibir tanto las leyes eclesiásticas, como las políticas y civiles en ellos ordenadas» ${ }^{4}$.

Las decisiones y disposiciones adoptadas de consuno por los nobles y prelados en materias de Estado tenían plena eficacia jurídica,

${ }^{1}$ PACHECO, J. F., «Introducción», Códigos españoles, Madrid, 1847, p. XXX.

${ }^{2}$ MARTÍNEZ MARINA, F., Teoría de las Cortes, I, 10.

${ }^{3}$ El día de las exequias por el óbito de Recesvinto (1-IX-672), fallecido en Gérticos -lejos de Toledo-, su sucesor, Wamba, fue proclamado rey visigodo por los magnates y obispos presentes y el pueblo de esta villa.

${ }^{4}$ COLMEIRO, M., De la constitución y del gobierno de los reinos de León y Castilla, Madrid, 1855, pp. 59-60.

(C) UNED. Revista de Derecho UNED, núm. 22, 2018 
en virtud de las leges in confirmatione concilii del monarca ${ }^{5}$, sin perjuicio de que el rey conservara la autoridad para promulgar motu proprio leyes civiles ${ }^{6}$.

Antes de la conversión de Recaredo, el poder político toleró las creencias discrepantes con la doctrina teológica arriana, la jerarquía eclesiástica mantuvo incólume su potestad sobre los asuntos e intereses de la Iglesia católica y las esferas temporal y celestial estaban perfectamente deslindadas.

Sin embargo, desde que el catolicismo se convirtió en la religión oficial de la monarquía visigoda, se declararon heréticas y se persiguieron las demás confesiones religiosas. Se produjo, además, un debilitamiento de la autoridad regia: su tradicional poder absoluto periclitó en favor de los prelados, que intervenían en la adopción de las decisiones políticas del Reino.

«La monarquía goda, en efecto, en su primer período hasta Teodoredo, en su segundo período hasta la muerte de Leovigildo, fue completamente ilimitada y absoluta; desde Recaredo en adelante los concilios y el poder episcopal, si no de derecho, de hecho la limitaron. Miéntras que fué nómada desde Atanarico hasta Walia, miéntras que fué arriana, aunque estable y permanente, los reyes ejercieron un completo y omnímodo poder, sin más correctivo que los movimientos anárquicos y el puñal de las conjuraciones. En la última época del Estado, convertidos ya sus jefes al catolicismo, verdad es que ninguna ley concedió autoridad temporal á la Iglesia, pero también es cierto que los monarcas se la dejaron tomar, y que depusieron su corona y entregaron su cetro en manos de aquellas orgullosas asambleas, tan célebres en nuestros antiguos anales» ${ }^{7}$.

La más conspicua función que asumieron los concilios toledanos fue la designación regia, cifrada en la dialéctica sucesión electiva-sucesión hereditaria: «(...) una continua lucha entre el principio de sucesión electiva al trono y los repetidos intentos de no pocos reyes de convertir de facto aquella sucesión en hereditaria o, por lo menos, de designar en vida la persona del que había de seguirle en el ejercicio del poder soberano» ${ }^{8}$.

${ }^{5}$ ORLANDIS, J., «El poder real y la sucesión al trono en la monarquía visigótica», Estudios Visigóticos, vol. III, Madrid, 1962, p. 43.

${ }^{6}$ VALVERDE CASTRO, M. ${ }^{a}$. R., Ideología, simbolismo y ejercicio del poder real en la monarquía visigoda: un proceso de cambio, Ediciones Universidad de Salamanca, Salamanca, 2000, p. 227.

${ }^{7}$ PACHECO, J. F., op. cit., p. XIX.

${ }^{8}$ ORLANDIS, J., op. cit., p. 44. 
En el IV Concilio de Toledo (633) — "Concilio constituyente» ${ }^{9}$ - se fraguó el pacto entre prelados y aristócratas para determinar legalmente - canon LXXV- que el sistema sucesorio sería el electivo, con el fin de asegurar la estabilidad política del Reino ${ }^{10}$.

No obstante, aunque la designación era electiva la legitimación era divina: «(...) rijáis con justicia y piedad los pueblos que Dios os ha encargado, y deis cuenta a Cristo que os constituyó reyes (...)» ${ }^{11}$. De modo que la unción eclesial «tenía un valor constitutivo o al menos confirmante de la legitimidad real $»^{12}$.

Este rito solemne, inaugurado por el reino visigodo de Toledo en la Europa cristiana siguiendo los modelos del Antiguo Testamento, evidenciaba ante la comunidad de fieles su condición de elegido por la divinidad y revestía a la persona del monarca de carácter sacro $^{13}$.

Siguiendo las normas conciliares, una vez electo y ungido, el nuevo rey tenía que jurar «defender el reino y gobernar con justicia y moderación observando las leyes, reconocer el derecho de los súbditos a la posesión de las propiedades que hubieran recibido como donaciones regias, guardar una estricta separación entre los bienes propios y los de la corona y proteger la fe y la Iglesia católica» ${ }^{14}$.

Todos los hombres libres del Reino debían prestar juramento de fidelidad al monarca: los miembros del Aula Regia directamente ante el rey y el resto ante los discussores iuramenti, que se desplazaban por el territorio para recabar el compromiso de fidelidad ${ }^{15}$. El juramento del pueblo junto con su presencia en los concilios aclamando las dis-

${ }^{9}$ Este calificativo del IV Concilio está justificado porque en el canon LXXV se establecen las leyes fundamentales del Imperio gótico: monarquía electiva, valores y virtudes que debían adornar al monarca, sanciones espirituales y la fidelidad de los súbditos a la monarquía. Cfr. ORLANDIS, J. y RAMOS LISSÓN, D., Historia de los concilios de la España romana y visigoda, Ediciones Universidad de Navarra, Pamplona, 1986, pp. 261-298.

10 «Nadie se atreva a ocupar el trono por fuerza ni por engaño; nadie trate de matar al rey, sino que, en cuanto éste muera, reunidos los grandes con los obispos elegirán la persona que ha de ocupar el trono, porque unidos estos dos poderes, en voluntad y concordia, no resultará ningún daño al pueblo, ni por medio de la fuerza ni del cohecho» (Canon LXXV del IV Concilio de Toledo, citado por GONZÁLEZ, F. A., Colección de cánones de la Iglesia española, notas e ilustraciones Juan Tejada y Ramiro, tomo II, Madrid, 1850, p. 312).

${ }^{11}$ Canon LXXV del IV Concilio de Toledo, citado en ibidem, p. 313.

${ }^{12}$ ORLANDIS, J., op. cit., p. 55.

${ }^{13}$ Cfr. VALVERDE CASTRO, M. ${ }^{a}$. R. op. cit., p. 208.

${ }^{14}$ Ibidem, p. 217.

${ }^{15}$ Ibidem, p. 220. 
posiciones acordadas, reforzaba su legitimidad y los obligaba a su cumplimiento ${ }^{16}$.

En la última etapa de la monarquía visigoda arraigó el principio hereditario: el rey elegía a su sucesor y el concilio lo reconocía como legítimo. Este nuevo sistema de sucesión soslayaba el vacío de poder que se producía durante el período del interregno, en el cual el poder revertía a Dios - regnante Christo-, lo cual imprimía una mayor estabilidad al reino y desactivaba las luchas intestinas entre las familias nobiliarias, decreciendo su poder político ${ }^{17}$.

Los acuerdos conciliares y el preceptivo juramento real pretendían limitar el ejercicio del poder monárquico, mediante su sometimiento a la ley y la imposición de sanciones espirituales ${ }^{18}$. En efecto, no existía ninguna autoridad jurisdiccional legitimada para juzgar al rey en la tierra, en el caso de que su acción política estuviera enfrentada o reñida con las disposiciones conciliares. Como certeramente significa Valverde Castro: «No fue la teoría política la que limitó los poderes regios. Fue la realidad socioeconómica, presidida por una poderosa nobleza, la que condicionó y de alguna manera controló con sus sublevaciones el modo en que los reyes ejercieron las tareas de gobierno» ${ }^{19}$.

\section{I.B. Las Cortes del Reino de León}

En las tierras castellanas los concilios siguieron reuniéndose tras la invasión musulmana, conservando su naturaleza político-eclesiástica (ss. IX-XII). A finales del siglo XI, la Reforma gregoriana declaró la

${ }^{16}$ Cfr. Canon LXXV del IV Concilio de Toledo.

17 «(...) los hijos de los Reyes inspiran siempre mayor respeto y reverencia, no sólo a los propios, sino a los extraños, y aun hasta los mismos enemigos (...). Establecido, pues, el principio hereditario, se dan a la nación, en cierto modo, príncipes perpetuos, lo que no deja de ser en cierto modo bastante útil y saludable, pues con la continuación de un principado perfecto, se evitan las ambiciones, las grandes contiendas que suele haber o suscitarse en medio de las tempestades y turbulentos movimientos de un reino cuando se trata de la sucesión: todo lo que de necesidad exigiría si faltase el principio hereditario» (MARIANA, J. de, Del rey y de la institución real, I, 3).

${ }_{18}$ «(...) que si alguno de ellos por soberbia o fausto real, en contra de las reverencias de las leyes, ejerciere en los pueblos un poder muy despótico por maldades o codicia, sea condenado por Cristo Señor nuestro con la sentencia de anatema, y sea separado y juzgado por Dios, por haber tratado de obrar mal, y de convertir el reino en daño suyo" (Canon LXXV del IV Concilio de Toledo, citado por GONZÁLEZ, F. A., op. cit., pp. 313-314).

${ }^{19}$ VALVERDE CASTRO, M. ${ }^{\mathrm{a}}$. R., op. cit., p. 217. 
independencia de la Iglesia respecto al Emperador, sin embargo, los concilios mantuvieron su carácter político porque la Reconquista había fortalecido la alianza Iglesia-Poder temporal. La religión cristiana fue el aglutinante de los actores implicados — reyes, nobles y las Órdenes Militares de Santiago, Alcántara, Calatrava y Montesa- en la derrota del invasor musulmán.

Como el influjo romano era más atenuado al sur de los Pirineos que en otras partes de Europa, que no se encontraban inmersas en una cruzada de liberación, no se produjo una abrupta ruptura entre la monarquía visigoda y las feudales, surgidas en el fragor de la Reconquista, sino que progresivamente los concilios fueron perdiendo relevancia política. Con ello recuperaron su primigenia naturaleza espiritual, dominados enteramente por el alto clero.

Curia $^{20}$ fue el término empleado desde mediados del siglo XI para denominar al tradicional consejo del rey. Al igual que el aula regia visigoda, era una asamblea permanente formada por los vasallos laicos y eclesiásticos de mayor confianza real, cuya misión era la de asesorar al monarca en los asuntos cotidianos de gobierno.

El decaimiento político de los concilios provocó el sincrónico cambio en la denominación del órgano gubernativo: curia plena. El monarca seguía necesitando el asesoramiento de los magnaticios y los obispos para la adopción de las decisiones políticas más relevantes del reino.

La curia plena descendía de los concilios visigodos porque en la alborada de las monarquías feudales las asambleas políticas extraordinarias se denominaban concilia, y también debido a que se adoptó la terminología eclesiástica — decreta - para denominar a las disposiciones jurídicas aprobadas en la curia plena ${ }^{21}$.

La composición de la curia plena fue ampliándose progresivamente por medio de la incorporación de los miembros de la baja nobleza - milites - y de los boni homines, que representaban los intereses de las ciudades. La inclusión de estos últimos se produjo en la curia plena celebrada en la Colegiata de San Isidoro de León, durante el primer año del reinado del joven Alfonso IX (1188). Constituye el naci-

\footnotetext{
${ }^{20}$ Según Colmeiro, el origen etimológico de la palabra «cortes» se encuentra en la voz latina curia que «en romance significa palacio o corte, esto es, lugar donde el Rey tenía su residencia» (COLMEIRO, M. Cortes de los antiguos reinos de León y Castilla, I, 1).

${ }^{21}$ Cfr. ESTEPA DÍEZ, C., "Curia y Cortes en el Reino de León» en Las Cortes de Castilla y León en la Edad Media, vol. I, Cortes de Castilla y León, Valladolid, 1988, pp. 62-64.
} 
miento de las Cortes en Europa porque por primera vez estuvo representado el estamento popular, junto con el nobiliario y el eclesiástico.

La prueba documental de este hito en la historia del parlamentarismo europeo son los Decreta aprobados en las Cortes de León ${ }^{22}$, denominados la Carta Magna leonesa por establecer un nuevo modelo político basado en la participación de los tres estamentos en el gobierno del Reino de León. De esta forma se incorporó a los representantes de las ciudades al proceso de toma de decisiones políticas:

«Ego dominus Aldefonsus, Rex Legionis et Gallicie, cum celebrarem curiam apud Legionem cum archiepiscopo et episcopis et magnatibus regni mei, et cum electis civibus ex singulis civitatibus ${ }^{23}$.

Los Decreta son un conjunto de diecisiete normas jurídicas con las que Alfonso IX pretendía proteger a los súbditos de la arbitrariedad del poder nobiliario y poner fin a la violencia instalada en el Reino. Han llegado hasta nosotros - como otros textos jurídicosgracias a la labor de los juristas, que los recogieron en el Liber Iudiciorium $^{24}$.

\section{LA MONARQUÍA DUALISTA ESTAMENTAL}

La monarquía dualista estamental del Medievo se caracterizó por la dialéctica rey-reino, en la que latían dos elementos antagónicos, a saber, el teocrático — voluntas principis- y el feudal — pactum-. La faceta teocrática del rey implicaba que el pueblo le había sido encomendado por Dios para asegurar la paz y el orden público, sin que existiera relación o vínculo jurídico entre ambos. Las medidas político-legislativas eran decididas e impuestas por el arbitrio del monarca —quod principi placuit, habet legis vigorem-, sin el concierto ni la anuencia de los privilegiados de la sociedad medieval: concepción teocrática del gobierno y del Derecho. La voluntas rei era expresión de la voz de Dios y no existía ninguna instancia que limitara o contriñera su poder absoluto.

${ }^{22}$ Incluidos en el año 2013 en el Registro Memoria del Mundo de la Unesco.

${ }^{23}$ Citado por la página web del Ministerio de Educación y Ciencia de España, en la que se encuentra la transcripción latina de los Decreta (http://goo.gl/q6Cbaw, fecha de consulta: 17-VII-2017).

${ }^{24}$ Cfr. PRIETO PRIETO, A., "La autenticidad de los «decreta» de la curia leonesa de 1188», en Las Cortes de Castilla y León, 1188-1988: Actas del Congreso sobre la historia de las Cortes de Castilla y León, 1988, vol. I, Cortes de Castilla y León, Valladolid, 1990, p. 48. 
En cambio, la faceta feudal implicaba una relación contractual entre el monarca y los barones, de la que se derivaban importantes consecuencias. La concepción feudal del Derecho entrañaba limitaciones al poder real: protección de la propiedad privada, garantías procesales y la prohibición de la imposición de tributos. Así, pues, la promulgación de leyes no podía ser acordada por la autoridad regia, sino que necesariamente tenía que ser fruto del pactum entre el monarca y los prebostes, que actuaban en nombre de la comunidad.

El resultado de varios siglos de enfrentamientos arrojó una suerte dispar a los contendientes según los países: en España y Francia se impuso el monarca teocrático sobre los estamentos, lo que dio lugar en nuestro país a la monarquía absoluta de los Reyes Católicos. En efecto, tras vencer a los musulmanes y domeñar a los nobles castellanos, Isabel y Fernando instituyeron el Estado español sobre el sustrato de la religión católica y de la soberanía personal del monarca, que se convirtió en el representante material del Reino: "Cuerpo unitario que sólo se constituye con el Rey y en el Rey», de manera que los súbditos ya no eran «miembros del reino, sino del cuerpo místico del Rey ${ }^{25}$.

En Inglaterra, en cambio, venció el reino, representado por las Cámaras de los Comunes y de los Lores, lo que propició un gobierno mixto, fundado en la soberanía del parlamento - Rey, Lores y Comunes- y en el consecuente principio de legalidad (rule of law).

«[El Parlamento] representa y tiene el poder de todo el reino, de la cabeza y del cuerpo (...) están presentes todos los ingleses, ya sea personalmente o por representación, [de forma] que el consentimiento del Parlamento equivale al consentimiento del cada hombre (...) era el más alto y absoluto poder del reino de Inglaterra (...). El Parlamento abroga viejas leyes, las hace nuevas, da órdenes para cosas pasadas y venideras, cambia derechos y propiedades de los hombres, establece formas de religión, altera pesos y medidas, da normas de sucesión a la Corona, define derechos dudosos cuando falta la ley, concede subsidios, tallas, tasas e impuestos; da libérrimo perdón y absoluciones, rehabilita en sangre y en nombre, y como tribunal supremo condena o absuelve ${ }^{26}$

${ }^{25}$ MARAVALL, J. A., Las comunidades de Castilla, Revista de Occidente, Madrid, 1963, p. 128.

${ }^{26}$ SMITH, T., De Republica Anglorum. A Discourse on the Commonwealth of England (1583), II, 1, citado por VARELA SUANCES, J., «La soberanía en la doctrina británica (de Bracton a Dicey)», Fundamentos 1/1998 "Soberanía y Constitución», Oviedo, 1998, pp. 94 y 95. 
Como señala Varela Suances, «tal diferencia en la fundamentación doctrinal de la Monarquía tenía su correlato en el ámbito institucional: mientras en España apenas se convocaron Cortes durante esos siglos [XVI y XVII] y en Francia los Estados Generales dejaron de convocarse en 1614, las Cámaras de los Lores y de los Comunes siguieron manteniendo su presencia política durante esa época, a pesar del indudable reforzamiento del poder regio durante la época de los Tudores y Estuardos ${ }^{27}$.

«(...) mientras en la mayoría de los países continentales la concentración (de poder) tuvo lugar en manos del monarca, en Inglaterra se verificó en el Parlamento. La variación es primordialmente de titular, pero no de calidad de poder: al igual que el monarca continental, el Parlamento se hizo supremo, no ligado al Derecho anterior, sino superior a él; de la misma manera que en el continente se conservaron, a veces, formalmente las Cortes o los Estados Generales, pero quedando subordinados al monarca, de la misma manera, pero al revés, en Inglaterra el monarca quedó finalmente subordinado al Parlamento, hasta el punto de poderse definir la prerrogativa como el remanente de poder que el Parlamento ha dejado al Rey ${ }^{28}$.

\section{LA NATURALEZA REPRESENTATIVA DE LAS CORTES DE CASTILLA}

La legitimación divina del poder político de la Monarquía Hispánica implicaba que la naturaleza representativa de las Cortes de Castilla fuera jurídica y no política. En efecto, los procuradores castellanos no conferían una fundamentación racional o inmanente al poder legislativo; no ejercían ningún poder público - limitaban el poder absolutista real en la imposición de tributos y servicios-, ni representaban los intereses generales del Reino, sino los particulares o privados de los estados y corporaciones que integraban la sociedad jerarquizada del Antiguo Régimen.

«[Las Cortes] reproducen la imagen del Reino o, por decirlo de otra manera, lo hacen presente ante el soberano en la diversidad de corporaciones que lo constituyen. Los delegados de las comunidades que acuden a las asambleas de que se trate cada vez que el rey las convoca hacen fundamentalmente de portavoces de los intereses específicos de esas mismas comunidades. Es decir, Cortes, Parlamentos o Es-

${ }^{27}$ Ibidem, p. 92.

${ }^{28}$ GARCIA-PELAYO, M., Derecho Constitucional Comparado, Alianza, Madrid, 1984, pp. 250-251. 
tados Generales reproducen el particularismo propio de la estructura corporativa del reino» ${ }^{29}$.

Durante el Medievo las Cortes de Castilla estaban formadas por los procuradores de las ciudades con voto, que eran un gran número - a las Cortes de Burgos (1315) acudieron 200 procuradores de 100 ciudades y villas y a las de Madrid (1391) 125 procuradores de 49 ciudades y villas ${ }^{30}$ - y aquéllos miembros de los brazos nobiliario y eclesiástico a los que el rey potestativamente, en razón de la naturaleza y gravedad de los asuntos a resolver, convocaba por medio de la carta de llamamiento ${ }^{31}$.

En efecto, $a b$ initio los reyes convocaban a Cortes a los tres brazos, sin embargo, a partir del reinado de Sancho IV «fue muy corto el número de personas que de esas dos clases [nobles y eclesiásticos] concurrían regularmente a las Cortes y casi ninguna su autoridad en las determinaciones de los asuntos generales, políticos, económicos y gubernativos de la monarquía ${ }^{32}$. Por esta razón, Marina considera que el brazo popular fue considerado «la parte esencial y primaria de la representación política de los reinos» ${ }^{33}$ :

«Estas Cortes [Madrid, 1391], cuyas actas por fortuna se han conservado íntegras, prueban evidentemente que las resoluciones generales de nuestros antiguos congresos emanaban de la voluntad del pueblo representado por sus procuradores, y que la autoridad política estaba depositada exclusivamente en ellos. Pues aunque fueron llamados a estas insignes Cortes por el Rey y su consejo todos los grandes, condes y caballeros y los prelados, cuanto se ha actuado y determinado en ellas recibió su fuerza y vigor del Reino representado por los diputados de ciudades y pueblos» ${ }^{34}$.

El reconocimiento del derecho de representación política al tercer estado por los reyes de León y Castilla no pretendía favorecer o preservar los intereses de la incipiente burguesía castellana, sino instituir un sujeto político - las ciudades- que respaldara las políticas públicas regias y así postergar a los nobles y prelados, en orden a enervar su peraltado poder político y económico que ensombrecía la autoridad real. Las ciudades con voto en Cortes aprovecharon la coyuntura

${ }^{29}$ FORTEA PÉREZ, J. I., Las Cortes de Castilla y León bajo los Austrias. Una interpretación, Junta de Castilla y León, Valladolid, 2008, p. 365.

${ }^{30}$ COLMEIRO, M., Cortes de los antiguos..., op. cit., I, 4.

${ }^{31}$ Los aristócratas y los obispos no eran jurídicamente representantes de sus estamentos ya que no eran electos, sino designados por el rey, no obstante, los dos primeros brazos se consideraban representados por ellos.

${ }^{32}$ MARTÍNEZ MARINA, F., op. cit., I, 10.

${ }^{33}$ Ibidem, I, 11.

${ }^{34}$ Ibidem, I, 10. 
favorable para defender sus intereses e influir en la toma de decisiones regias a través de sus procuradores.

«No se olvide que durante buena parte del siglo Xv, prácticamente ininterrumpida la promulgación de cuadernos de leyes, los ordenamientos de Cortes surgen "a ynstançia», «a petiçión», a requerimiento y por iniciativa de los representantes de las ciudades. Con otras palabras: los procuradores son los verdaderos orientadores de la política legislativa que la monarquía desarrolla en las Cortes» ${ }^{35}$.

A los sucesivos monarcas de la Casa Trastámara también les importunaba la masiva presencia de las ciudades en las Cortes, porque dilataba la discusión de los asuntos públicos y dificultaba la concesión de nuevos impuestos y servicios. Por ello, partir del siglo Xv los reyes modificaron la naturaleza jurídica del voto de las ciudades en Cortes, a saber, de ser un derecho pasó a convertirse en un privilegio que graciosamente concedía el monarca.

En el tránsito del Medievo a la Modernidad, las ciudades plantearon una reivindicación política que dio la puntilla a la presencia de los dos primeros estamentos en las Cortes: "Las ciudades con voto empezaron a reclamar la representación del conjunto de las provincias de las que eran capitales, y no sólo de sus tierras, con independencia de la condición jurisdiccional de los territorios integrados en aquéllas (...). La nueva posición de las ciudades habría hecho superflua la presencia de señores de vasallos y clérigos por cuanto unos y otros eran representados por las ciudades de que se tratara en tanto que cabezas de las provincias en donde se enclavaban los territorios de los que aquéllos eran señores» ${ }^{36}$.

Esta reivindicación fue atendida y las Cortes de Toledo de 1538-39 fueron las últimas a las que el rey convocó a los miembros de los estamentos nobiliario y eclesiástico ${ }^{37}$.

La obstinación de las ciudades con voto en oponerse a que el monarca extendiera este privilegio a otras acentuó el carácter particularista de las Cortes. La razón radicaba en que a las oligarquías urbanas, que dominaban los regimientos, les favorecía sobremanera este nuevo modelo ya que les resultaba más fácil que el rey atendiera sus peticiones ${ }^{38}$. Sin

${ }^{35}$ GONZÁLEZ ALONSO, B., op. cit., pp. 235 y 236.

${ }^{36}$ FORTEA PÉREZ, J. I., op. cit., p. 367.

${ }^{37}$ ESCUDERO, J. A., Curso de Historia del Derecho, Solana e Hijos, Madrid, 1995, p. 539.

${ }^{38}$ A las Cortes de Toledo de 1480 sólo fueron convocadas diecisiete ciudades con el pragmático argumento de que «solamente algunas y principales gozaban la preeminencia de resumir en los casos ordinarios la representación de los reinos de Castilla» (COLMEIRO, M., Las Cortes de los antiguos..., op. cit., I, 4). 
embargo, la preservación de sus intereses singulares se vio severamente dificultada a partir de 1520, porque Carlos I estableció que los ayuntamientos tenían que otorgar a sus dos procuradores poderes plenos y absolutos.

Esta exigencia real puede parecer - prima facie - un precedente de la idea moderna de representación política, en el sentido de que pretende sustituir el mandato imperativo, que ligaba al procurador con su ciudad, por el representativo, que no sólo libera de esa vinculación al mandatario sino que cada uno de los procuradores representa al conjunto del Reino, lo que les impone la adopción de aquellas decisiones políticas que favorezcan los intereses generales.

Sin embargo, no fue más que una argucia política de un rey absolutista para controlar las Cortes, dado que ejercía una gran influencia municipal que le aseguraba la elección de procuradores cortesanos, a lo que hay que adicionar las ayudas de $\operatorname{costa}^{39} \operatorname{con}$ las que cohechaba la voluntad de los procuradores, con el fin de que aprobaran sus pretensiones de aumento de servicios o impuestos, a los que tendrían que hacer frente las ciudades.

\section{MANDATO IMPERATIVO VERSUS MANDATO REPRESENTATIVO}

La presencia política de las ciudades en las Cortes se articuló en la figura de los procuradores. Estos «mensajeros de los concejos» ${ }^{40} \mathrm{o}$ «legados de las corporaciones» ${ }^{41}$ eran comisionados encargados de trasladar al rey la posición política de su cabildo mediante el sufragio - voto corporativo (cláusula in solidum ${ }^{42}$ ) - y de procurar que el monarca satisficiera los intereses de sus mandantes, plasmados en el cuaderno de peticiones.

«(...) se trataba de otorgarles poder suficiente no solamente para conferir, conceder o negar el asunto o proposición principal expresada en la convocatoria y que motivaba las Cortes, sino también para promover los intereses de los concejos y cuanto podía conducir a su prosperidad y al bien general ${ }^{43}$.

${ }^{39}$ Un suerte de dietas que devengaban los procuradores por cada día de sesión de Cortes, imprescindibles para su subsistencia ya que las ciudades les solían abonar un magro salario.

${ }^{40}$ COLMEIRO, M., Las Cortes de los antiguos..., op. cit., I, 4.

${ }^{41}$ ARTAZA, M. M. de, Rey, reino y representación. La Junta General del Reino de Galicia, CSIC, Madrid, 1998, p. 92.

${ }^{42}$ Ambos procuradores debían votar de consumo para que el voto fuera válido.

${ }^{43}$ MARTÍNEZ MARINA, F., op. cit., I, 23. 
La elección del procurador era un acto en virtud del cual se constituía la representación jurídica de los intereses patrimoniales o económicos de la corporación municipal en la figura del representante, sobre la base del mandato privado y, por tanto, de carácter imperativo ${ }^{44}$ : un apoderamiento limitado a una serie de asuntos o materias en los que debía actuar conforme a unas instrucciones perfectamente definidas, fijadas en la carta de creencia o de procuración ${ }^{45}$.

En este documento público, que el procurador debía presentar en las Cortes, constaba su designación y los poderes que le habían sido conferidos. Cuando se trataban asuntos diferentes a los fijados en la convocatoria de Cortes, el mandatario se retiraba a su ciudad para recibir nuevos poderes; y en caso de duda sobre el sentido de las instrucciones, debía obrar de la misma forma. Asimismo, debía informar periódicamente al ayuntamiento de la evolución y desarrollo de las sesiones, por si consideraba oportuno ampliar los poderes o modificar los vigentes.

En cuanto a las consecuencias jurídico-políticas dimanantes de la infracción de los poderes especiales, concretos y limitados concedidos por la corporación, hay que señalar dos derivados de su concepción iusprivatista, a saber, la revocación del mandato imperativo y la exigencia de responsabilidad.

La revocación de los poderes debía ser acordada por el cabildo en los supuestos de hecho que considerase determinantes de haberse quebrado la relación de confianza con el procurador, base de su nombramiento, ad exemplum: la infracción de la obligación de informar o la vulneración de los poderes otorgados. En este caso, el mandatario ya no estaba legitimado para vincular al cabildo, debiendo nombrar a un sustituto y conferir nuevos poderes ${ }^{46}$.

44 «Apoderamiento que se confiere para tratar una lista cerrada de asuntos, a la que añaden las instrucciones conforme a las cuales han de ser gestionados por los procuradores» (SARRIÓN GUALDA, J., "La interferencia del rey en la designación y poderes de los procuradores en las Cortes castellano-leonesas (siglos XVI-XVII)», Homenaje al profesor Jesús Lalinde Abadía. Centralismo y Autonomismo en los siglos XVI y XVII, Ediciones Universidad de Barcelona, Barcelona, 1989, p. 377).

${ }^{45}$ La designación del mandatario «entrañaba un contrato sinalagmático entre el Concejo mandante y el Procurador mandatario, otorgando aquél a éste un poder amplio, sí, pero especial y condicionado por instrucciones precisas, a las cuales debía ajustarse el apoderado en el desempeño de su cargo» (BOFARRULL Y ROMAÑÁ, M., Las antiguas Cortes. El moderno parlamento. El régimen representativo orgánico, Alcalá de Henares, 1945, p. 39)

${ }^{46}$ Cfr. ARTAZA, M. M. de, op. cit., p. 92, nota 112. 
$\mathrm{Al}$ regresar de las Cortes el procurador tenía que someterse al juicio de residencia ${ }^{47}$ : una comparecencia pública en la que tenía que rendir cuentas de su actividad parlamentaria. Los miembros de la corporación o cualquier persona podían presentar quejas o denuncias en el acto contra el representante por incumplimiento de sus funciones institucionales, y, en caso de resultar acreditada, tenía que hacer frente a las consiguientes responsabilidades jurídicas.

Así, pues, la representación estamental del Antiguo Régimen fue una institución jurídica de naturaleza híbrida: inspirada, por una parte, en el derecho privado (tutela de intereses particulares y patrimoniales, instrucciones previas, revocación y rendición de cuentas) y, por otra, en el derecho público, ya que el procurador era una autoridad que recibía su apoderamiento de una corporación municipal, protocolizado por los escribanos que daban fe de los términos del mismo, y, finalmente, debía prestar juramento ante el ayuntamiento para tomar posesión del cargo ${ }^{48}$.

A partir de la reforma política de Carlos I en 1520, las cartas de convocatoria de Cortes exigían que los ayuntamientos concedieran a los procuradores "poder complido, libre, llenero y bastante, según que mejor y más cumplidamente podemos dar (...) para (...) ver, tratar y platicar (...) y consentir y otorgar y hazer y concluir por Cortes» ${ }^{49}$.

En las convocatorias de Cortes el rey mencionaba expresamente la doble condición de los procuradores: como mandatarios de las ciudades preservarían sus intereses intentando que el monarca les concediera las peticiones recogidas en el cuaderno; y como minis-

${ }^{47}$ Esta institución fue incorporada al derecho público por el cardenal español don Gil Álvarez de Albornoz, fundador del Real Colegio de España en Bolonia, en Las Constituciones Egidianas (III, 24), promulgadas en 1354 (citado por José Guillermo García-Valdecasas y Andrada-Valderwilde, Rector del Real Colegio de España, en uno de los almuerzos celebrados en la Casa de don Gil durante la primavera de 2015).

48 «Los tales procuradores después de que así fuesen elegidos e nombrados juren asimismo solemnemente cuando les fuere dado el poder que non ficieron nin farán cosa alguna contra lo contenido en esta lei, e que usarán del dicho poder justa y derechamente, e que en el dicho oficio guardarán el servicio de Dios e el provecho e bien público de las cibdades e villas que los enviaren... e non pedirán absolución nin dispensación del dicho juramento, nin usarán de ella aunque les sea otorgada de propio motu, e non dejarán de facer e cumplir lo susodicho por amor nin por temor nin por premio alguno nin por interese nin provecho que por ello les den o esperen ellos o cualesquier parientes o amigos suyos (...)»(MARTÍNEZ MARINA, F., op. cit., I, 21).

${ }^{49}$ Citado por THOMPSON, I. A. A., "Cortes y ciudades: tipología de los procuradores (extracción social, representatividad)», en Las Cortes de Castilla y León en la Edad Moderna, Valladolid, 1989, p. 209. 
tros del reino velarían por el bien general votando con altura de miras, sin estar mediatizados por las conveniencias de su ciudad ${ }^{50}$. Difícil cometido tenían ante sí: conciliar intereses particulares y generales, máxime si tenemos en cuenta que se encontraban entre dos feroces contendientes: las ciudades no estaban dispuestas a entregar en manos de los procuradores el poder político decisivo que se había residenciado tradicionalmente en sus órganos de gobierno; y la Corona pretendía quebrar la configuración medieval de las Cortes, alentando constantemente a que los procuradores se erigieran en voz de todo el Reino.

La restricción del poder municipal, la ausencia del monarca, el nombramiento de extranjeros para cargos públicos y la concesión de servicios para misiones foráneas que no interesaban a los castellanos, obtenidos en las Cortes de 1520 violentando la voluntad de los procuradores, produjeron la Revuelta de las Comunidades: «Primera revolución de carácter moderno en España y probablemente en Europa ${ }^{51}$.

La derrota de los Comuneros acentuó el absolutismo regio y debilitó la posición institucional de las Cortes, cuya convocatoria se fue reduciendo en los sucesivos reinados de la dinastía Habsburgo, y el poder político de las ciudades: se restringió el derecho a recibir información del desarrollo de las Cortes y la facultad interpretativa de los poderes emitidos quedó supeditada a la autorización regia ${ }^{52}$.

Algunas ciudades, a pesar de expedir un poder conforme al tenor literal demandado en la convocatoria regia, recelaron de conceder el mandato representativo a sus mandatarios, porque sabían que no defenderían sus intereses sino los del monarca, gracias a las mercedes que prodigaba para domeñar su voluntad de acuerdo a sus designios.

Estos cabildos mantuvieron en la práctica el mandato imperativo mediante la institución del juramento del pleito homenaje. Acto público en el que el mandatario declaraba solemnemente su compromiso de acatar las instrucciones de la ciudad:

«I. Que el procurador se presentase ante el rey, besando sus manos en prueba de reverencia, y a continuación se uniese al Reino junto en Cortes para tratar sobre las cosas que redundaran en beneficio de Dios, del rey y de los reinos.

${ }^{50}$ FORTEA PÉREZ, J. I., op. cit., p. 376.

${ }^{51}$ MARAVALL, J. A., Las comunidades de Castilla, op. cit., p. 13. Cfr. «Prólogo», pp. 11-21.

${ }^{52}$ MARTÍNEZ MARINA, F. op. cit., I, 23. 
II. Que durante el tiempo que durasen las Cortes, el procurador no se ocupe de negocios propios, ni pida o reciba cualquier merced real, aunque el Rey nuestro Señor se la ofrezca.

III. Que no se conceda ningún servicio sin informar previamente al ayuntamiento, y sin tener licencia de éste para ello. Esto se hace extensivo a otros asuntos.

IV. Que jure no pedir a la ciudad ni a su partido ningún salario ni ayuda de costa más que los 4.000 maravedíes que solían concederles» ${ }^{53}$.

Así, pues, cuando el rey pretendía aprobar un servicio o impuesto los procuradores que habían jurado el pleito homenaje o bien lo concedían con voto consultivo - sin eficacia jurídica - e informaban a sus ayuntamientos para que procedieran a votar la medida; o bien se negaban a votar hasta que resolviese el cabildo. Si éste lo aprobaba, como ocurría habitualmente, se procedía al levantamiento del pleito homenaje y «los procuradores hacen constar que se hace [la concesión] en nombre de la ciudad y con su consentimiento» ${ }^{54}$.

La dicotomía voto consultivo-voto definitivo, que al principio sólo tenía incidencia en las ciudades que habían limitado el poder de los procuradores sometiéndolo a las instrucciones contenidas en el pleito homenaje, se pretendió hacerlo extensivo, mediante una protesta del Reino junto en Cortes, a todas las ciudades en las primeras Cortes de Felipe III (1599). En 1618 se reconoció finalmente el derecho al voto decisivo de todos los cabildos ${ }^{55}$.

${ }^{53}$ CABALlERO VILLA, M. y PEDRUELO MARTÍN, E., «Relaciones ciudadprocuradores-rey: Valladolid, 1592-1621. El control de los procuradores» en Las Cortes de Castilla y León 1188-1988, vol. 1, op. cit., p. 480.

${ }^{54}$ Ibidem, p. 484.

55 «[el Reino] acordó de conformidad que ante todas cosas hace protestación de que ninguna de las cosas que tratare y acordare cerca del dicho servicio que se ha de hacer a S.M., ni lo que los caballeros procuradores de estas Cortes dixeren y votaren en él, no obligue a las ciudades y villas de voto en Cortes, ni a estos Reynos, ni les perjudique, ni a alguno de los estados de ellos, ni a las libertades que ellos y las ciudades, villas y lugares de ellos deben y pueden gozar, sino que sólo ha de ser para dirección de lo que se trata, para cuando se llegare a consultarse con las ciudades por los votos consultivos de los procuradores de estas Cortes, den el que tuviere de ellas, porque se les ha de dexar, como se les dexa, libres sus votos decisivos, sin que queden obligadas a pasar por lo que en los votos consultivos dixeren sus procuradores, y con que todos queden y esten libres para que cuando se haya de votar decisivamente pueda cada uno dar el voto que su ciudad o villa le ordenare, aunque sea en contrario de lo que en los votos consultivos hubieren dado, porque todo lo que se tratare y platicare ha de ser para escribirles y darles cuenta de todo y hacer lo que ordenaren, y no en otra forma ni manera, y que en todos los votos que los dichos procuradores dieren en este negocio sea visto, y en cada uno inserta esta protestación», citado por THOMPSON, I. A. A., op. cit., p. 213. 
En la carta de convocatoria de las Cortes de 1632, Felipe IV exigió a los procuradores el voto definitivo -mandato representativo-, reclamando expresamente que acudieran con poder decisivo: «Consentir, otorgar, hacer y concluir decisivamente todo lo que en las dichas Cortes se propusiere, sin que sea necesario consultarles [a las ciudades] en ninguna de las dichas materias», con lo que «las Cortes de las ciudades se transformarían en las Cortes de los procuradores, y las ciudades se reducirán a meros ejecutores de lo que las Cortes resolviesen ${ }^{56}$.

Esta pretensión regia fue impugnada por la mayoría de los procuradores presentes en las Cortes de 1632, pero finalmente se impuso -no sin esfuerzo - la voluntad real: "Fueron menester nada menos que siete mandatos regios, en el 4, 13, 16, 20, 24, 27 y 29 de marzo, antes de que los procuradores cedieran frente a una cédula real mandándoles "que en todos los acuerdos hiziesse (...) assi en las resoluciones principales como en lo que a ellas precediesse y se siguiesse, votasse conforme a los poderes y a las órdenes que Su Magd tenía dado sobre esto independientemente de VS y demás ciudades que tienen voto en Cortes y sin condición, en lo que no pudiesse aver arbitrio, y prohibiendo que ningún Procurador votasse de otra manera, pues sería ir contra su propio poder" ${ }^{57}$.

Para asegurar mejor el cumplimiento de esta orden, además de condicionar el acceso a las sesiones de las Cortes a la previa comprobación de los poderes que portaban, se exigió a los procuradores la prestación del siguiente juramento:

«Juran a Dios y santa María y a la santa cruz y a las palabras de los santos cuatro vangelios; y hacen pleito homenage de que su ciudad no les ha dado instrumento, instrucción ni otro despacho que restringa o limite el poder que tienen presentado, ni orden pública o secreta que le contravenga, y que si durante las cortes les dieren alguna que se oponga a la libertad del poder, lo revelarán y harán notorio al presidente de Castilla que fuere y asistentes de las cortes, para que provean lo que más sea del servicio de s. m. Asimismo, juran que no traen pleito homenage en contrario de lo que suena y dispone el poder ${ }^{58}$.

La apuesta de la Monarquía Hispánica por las Cortes del Reino fue arropada con dos medidas consecuencia de la abrogación del voto decisivo de las ciudades. La Corona no consideraba «necesario que concurrieran ambos procuradores de qualquiera de las dichas ciuda-

${ }^{56}$ Citado en ibidem, pp. 216 y 217.

${ }^{57}$ Citado en ibidem, p. 218.

${ }^{58}$ MARTÍNEZ MARINA, F., op. cit., I, 23. 
des y villas para que se entienda haber venido la mayor parte» ${ }^{59}$, y el sometimiento de las ciudades a la decisión mayoritaria, sin poder exonerarse de las obligaciones dimanantes de sus acuerdos so pretexto de que sus representantes no habían votado a favor de ellas, ya que «no puede haber duda — señalaba el rey-que la mayor parte de los votos personales constituye reino y que lo que acuerda a de otorgar y firmar la otra parte que no hubiere concedido ${ }^{60}$.

Sin embargo, este nuevo diseño político-institucional de las Cortes no llegó a fraguar a causa de la férrea oposición de las ciudades a expedir poderes plenos y decisivos a sus representantes. Después de 1665 , las Cortes dejaron de convocarse, prueba inequívoca de la victoria de las ciudades sobre la Monarquía Hispánica. A partir de entonces, para solicitar nuevos servicios la Corona cursaba la petición individualizada a cada ayuntamiento.

${ }^{59}$ Cédula real de 12 de julio de 1632, citado por FORTEA PÉREZ, J. I., op. cit., pp. 379-380.

${ }^{60}$ Cédula real de 12 de julio de 1632, citado en ibidem, p. 380. 